\title{
FOLHAS VERDES DE FEIJÃO NA ALIMENTAÇÃO HUMANA: AVALIAÇÃO SENSORIAL, ADUBAÇÃO NITROGENADA E DESFOLHAMENTO(1)
}

\author{
SARAH VERRA DE FONSECA ${ }^{(2,4)}$; CLIBAS VIEIRA ${ }^{(2,4)}$; VALÉRIA PAULA \\ RODRIGUES MINIM ${ }^{(3)}$; ANTONIO AMÉRICO CARDOSO ${ }^{(2,4)}$
}

\begin{abstract}
RESUMO
Com o objetivo de estudar a possível utilização de folhas verdes de feijão-comum na alimentação humana, desenvolveram-se um experimento em Viçosa e dois em Coimbra, na Zona da Mata de Minas Gerais, na safra agrícola 1999/2000, utilizando-se o delineamento de blocos ao acaso, com quatro repetições. No experimento de Viçosa, utilizaram-se seis cultivares em testes sensoriais e na obtenção das produções de folhas verdes. No primeiro experimento de Coimbra, estudaramse os efeitos da adubação nitrogenada nas cultivares Ouro Negro e Pérola, submetidas a 33\% de desfolhamento, do estádio da floração até o início da formação de vagens. No segundo experimento de Coimbra, observaram-se os efeitos de três níveis de desfolhamento (33\%, 66\% e 100\%), combinados com quatro épocas de desfolhamento $(25,40,55$ e 70 dias após a emergência), mais uma testemunha (sem desfolhamento), na cultivar Ouro Negro. Verificou-se aceitação das folhas verdes da maioria das cultivares de feijão semelhante à da couve. Com 33\% de desfolhamento, tem-se rendimento de 0,4 a 1,5 t/ha de folhas verdes de feijoeiro. A composição química dessas folhas assemelha-se à da couve. Com a adubação nitrogenada são proporcionadas maiores produtividades de folhas verdes, de proteína (nas folhas) e de grãos. A época mais adequada para a coleta de folhas é antes do florescimento, não devendo o desfolhamento ultrapassar o nível de 33\%.

Palavras-chave: Phaseolus vulgaris, Brassica oleracea var. acephala, desfolhamento, avaliação sensorial, adubação nitrogenada, rendimento de folhas verdes.
\end{abstract}

\section{ABSTRACT \\ GREEN LEAVES OF COMMON BEANS IN HUMAN NUTRITION: SENSORIAL EVALUATION, NITROGEN FERTILIZATION AND DEFOLIATION}

In order to study the potential use of common bean green leaves in human nutrition, three experiments were carried out in 1999/2000, one in Viçosa and two in Coimbra, municipalities of the Zona da Mata area, State of Minas Gerais. A complete randomized block design with four replications was used. Six cultivars from Viçosa experiment were used for both sensorial test and determination of green leaves production. In Coimbra's first experiment, the effect of nitrogen fertilization on the cultivars Pérola and Ouro Negro was evaluated, when both were submitted to $33 \%$ defoliation at flowering until the pod-filling stage. In Coimbra's second experiment, a factorial of three levels of defoliation $(33 \%, 66 \%$, and $100 \%) \times$ four plant ages $(25,40,55$, and 70 days after plant emergence) plus a control treatment (no defoliation) was analysed using the cultivar Ouro Negro. It was verified that green leaves of most bean cultivars had an acceptance similar to that of collard leaves (Brassica oleraceae var. acephala), a popular vegetable in Brazil. Common beans could yield from 0.4 to $1.5 \mathrm{t}$ / ha of green leaves with $33 \%$ defoliation. Chemical composition of these leaves was similar to that of collard leaves. Nitrogen fertilization increased the yield of green leaves, seeds and leaf protein. The most adequate time for defoliation was before flowering and should not exceed $33 \%$.

Key words: Phaseolus vulgaris, Brassica oleracea var. acephala, defoliation, sensorial evaluation, nitrogen fertilization, green leaves yield.

(1) Parte da tese de Mestrado da primeira autora, apresentada à Universidade Federal de Viçosa. Recebido para publicação em 7 de novembro de 2001 e aceito em 31 de maio de 2002.

$\left(^{2}\right)$ Departamento de Fitotecnia, Universidade Federal de Viçosa (UFV), 36571-000 Viçosa (MG). E-mail: cbvieira@mail.ufv.br, aacardoso@mail.ufv.br

(3) Departamento de Tecnologia de Alimentos, UFV. E-mail: vprm@mail.ufv.br

$\left({ }^{4}\right)$ Com bolsa de produtividade científica do CNPq. 


\section{INTRODUÇÃO}

O feijoeiro (Phaseolus vulgaris L.) é planta originária do Novo Mundo e cultivada, atualmente, em todos os continentes, sobretudo para a produção de sementes secas; há, porém, cultivares próprias para a colheita de vagens verdes que, para tanto, devem ser macias e desprovidas de fibras.

Em certos países da África consomem-se, além dos grãos e vagens, as folhas verdes (EDJE et al., 1972; Mughogho et al., 1972; LAMB et al., 1985). No Malaui, as folhas são geralmente colhidas antes da produção de vagens e consumidas cozidas, refogadas ou secas (Mughogho et al., 1972). Segundo LAMB et al. (1985), o feijão é importante ingrediente na dieta da população de Ruanda, sendo utilizado como grão seco, grão imaturo, vagem verde e folha imatura.

A fim de verificar a aceitabilidade das folhas verdes de feijão na alimentação humana são realizados testes sensoriais, nos quais suas folhas são comparadas às de uma verdura amplamente aceita no País.

Como o consumo de folhas verdes de feijão implica desfolhamento das plantas e redução de sua área foliar, há que se considerar algum trato cultural com o qual seus danos sejam minimizados. Assim, constatou-se na África aumento tanto da produção de grãos como de folhas verdes apenas pelo efeito de adubação nitrogenada (EDJE et al., 1976; EDJE e Mughogho, 1976).

Os objetivos deste trabalho foram avaliar a aceitabilidade das folhas verdes de feijão na alimentação humana, no Brasil, por meio de testes sensoriais, utilizando-se como padrão de referência as folhas de couve (Brassica oleraceae var. acephala); verificar o efeito da adubação nitrogenada na produção de folhas verdes e de grãos do feijoeiro, e determinar até qual estádio de desenvolvimento dos feijoeiros pode-se efetuar o desfolhamento, bem como a porcentagem da área foliar que pode ser coletada em cada estádio, sem prejuízo à leguminosa.

\section{MATERIAL E MÉTODOS}

Para obtenção de folhas verdes de feijão para os testes de aceitabilidade sensorial, instalou-se, em 27/ 12/1999, um experimento em Viçosa, utilizando-se as cultivares Manteigão Fosco, Ouro Negro, Diacol Calima, Pérola e Ouro e a linhagem Vi. 13-8-3. Preparou-se o terreno com uma aração seguida de duas gradagens.

O delineamento experimental adotado foi o de blocos ao acaso, com quatro repetições. Cada parcela foi constituída por quatro fileiras de $4,0 \mathrm{~m}$ de comprimento, espaçadas de 0,5 m, com aproximadamente 15 sementes por metro de sulco. As duas linhas laterais, bem como 0,2 m de cada uma das extremidades das linhas centrais, foram consideradas como bordadura.

$\mathrm{Na}$ semeadura, todas as parcelas receberam 500 kg.ha-1 de 4-14-8 (N- $\left.\mathrm{P}_{2} \mathrm{O}_{5}-\mathrm{K}_{2} \mathrm{O}\right)$, nos sulcos de semeadura. Aos vinte dias após a emergência, isto é, no estádio V3 da classificação de estádios de desenvolvimento proposto por FERNÁNDEZ et al. (1982), aplicaram-se, em cobertura, $30 \mathrm{~kg} \cdot \mathrm{ha}^{-1}$ de N, na forma de uréia.

Realizou-se o controle da flora infestante com enxada até o estádio R5 (pré-floração), com capinas sucessivas. Sempre que necessárias, as irrigações foram realizadas. No início do desenvolvimento da cultura, as cigarrinhas-verdes (Empoasca kraemeri) foram controladas com Decis.

Em 14/2/2000, na época da formação das vagens, isto é, no estádio R7, fez-se o desfolhamento das cultivares e da linhagem, retirando-se um folíolo verde de cada folha trifoliolada, o que corresponde à eliminação de, aproximadamente, $33 \%$ da área foliar das plantas. Os folíolos verdes foram coletados em todas as parcelas de cada cultivar, em todas as repetições, pesados e colocados em refrigerador para a realização dos testes sensoriais no dia seguinte. Para esses testes, misturaram-se os materiais de cada cultivar proveniente das quatro repetições.

$\mathrm{Na}$ análise sensorial das folhas verdes de feijão, utilizaram-se como padrão de comparação folhas de couve: verdura de ampla aceitação nacional, adquiridas na feira local. Na preparação, retirou-se a nervura central das folhas da couve, enquanto as folhas de feijão foram totalmente utilizadas. As folhas foram picadas, refogadas e temperadas de maneira semelhante, com alho e sal; em seguida, serviram-nas a 70 provadores, que as avaliaram utilizando uma escala hedônica de nove pontos, em que 9 significa gostei extremamente; 8 , gostei muito; 7 , gostei moderadamente; 6 , gostei ligeiramente; 5 , indiferente; 4, desgostei ligeiramente; 3, desgostei moderadamente; 2 , desgostei muito; e 1, desgostei extremamente. Os dados foram analisados obedecendo-se ao delineamento de blocos incompletos balanceados, conforme CocHRAN e Cox (1957), com os seguintes parâmetros: $t=7$ (número total de amostras analisadas), $\mathrm{k}=3$ (número de amostras testadas em cada sessão pelo provador), $r=3$ (número de vezes que o provador testa cada amostra, ou seja, número de repetições), $B=7$ (número de blocos ou sessões realizadas) e $\lambda=1$ (número de vezes em que as amostras são testadas juntas numa mesma sessão). 
No primeiro experimento, desenvolvido em Coimbra, avaliou-se o efeito da adubação nitrogenada e do desfolhamento em solo previamente preparado de forma convencional, com uma aração e duas gradagens, e com deficiência de nitrogênio, revelada em análises anteriores.

Na semeadura, executada na segunda quinzena de março de 2000, utilizaram-se duas cultivares de feijão, para as quais se obteve maior aceitação pelos provadores na análise sensorial, quais sejam, Pérola e Ouro Negro.

Utilizou-se o delineamento de blocos ao acaso, com quatro repetições e tratamentos dispostos no fatorial $2 \times 4$, ou seja, duas cultivares (Pérola e Ouro Negro), combinadas com quatro doses de $\mathrm{N}(0,30$, 60 e 90 kg.ha-1 ${ }^{-1}$, sendo $1 / 3$ de cada dose aplicada, na forma de sulfato de amônio, em três épocas: na semeadura (sulco) e aos 20 e 27 dias após a emergência das plântulas.

Cada parcela experimental foi constituída de quatro linhas de 5,0 $\mathrm{m}$ de comprimento, espaçadas de $0,5 \mathrm{~m}$, com proximadamente 15 sementes por metro. Todas as parcelas receberam nos sulcos de semeadura $100 \mathrm{~kg} \cdot h \mathrm{~h}^{-1}$ de $\mathrm{P}_{2} \mathrm{O}_{5}$ (superfosfato simples) e $50 \mathrm{~kg} \cdot \mathrm{ha}^{-1} \mathrm{de}_{2} \mathrm{O}$ (cloreto de potássio). Na colheita, aproveitaram-se apenas as duas fileiras centrais.

Os tratos culturais foram os normais da cultura, com capinas manuais, tratamentos fitossanitários e irrigações, quando necessários.

O desfolhamento foi realizado aos 60 dias após a emergência, no estádio R6 (floração). Retirou-se um folíolo de cada folha trifoliolada, correspondendo a $33 \%$ de desfolhamento, aproximadamente.

De cada parcela experimental, as variáveis analisadas foram o estande final, a produção de folhas verdes, a produção de grãos e o teor de proteína nas folhas verdes, conforme o método de Kjeldahl (SiLva, 1990).

Uma amostra de folíolos coletados em todas as parcelas foi seca e analisada quimicamente, conforme SILVA (1990). Realizou-se o mesmo procedimento com a couve. Os folíolos de feijão foram analisados sem a eliminação prévia de suas nervuras centrais.

No segundo experimento de Coimbra, instalado em $7 / 5 / 2000$, em solo preparado por uma aração seguida de duas gradagens, aplicaram-se 600 kg.ha-1 de 4-14-8 nos sulcos de semeadura mais 40 kg.ha-1 de $\mathrm{N}$ (uréia) em cobertura, 30 dias após a emergência, ou seja, no estádio V4 (terceira folha trifoliolada) próximo ao R5 (pré-floração).

O delineamento experimental foi o de blocos ao acaso, com quatro repetições, e segundo o esquema fatorial $(4 \times 3)+1$, isto é, quatro épocas de desfolhamento $(25,40,55$ e 70 dias após a emergência) combinadas com três níveis de desfolhamento $(33 \%, 66 \%$ e $100 \%)$ mais a testemunha sem desfolhamento. As parcelas experimentais constituíram-se de quatro fileiras de $5,0 \mathrm{~m}$ de comprimento, espaçadas de $0,5 \mathrm{~m}$ e 10 a 15 sementes por metro da cultivar Ouro Negro. A área útil foi formada pelas duas fileiras centrais.

Obtiveram-se as porcentagens de desfolha, retirando-se, manualmente, de todas as plantas da parcela o folíolo central de todas as folhas, no nível de $33 \%$; os dois folíolos laterais, no nível de $66 \%$, e todos os três folíolos, no nível de $100 \%$. As épocas de desfolhamento corresponderam aos seguintes estádios de desenvolvimento do feijoeiro: início do V4 (terceira folha trifoliolada), R5 (pré-floração), R6 (floração) e R7 (formação das vagens).

O controle de plantas daninhas, os tratamentos fitossanitários e a irrigação foram realizados quando necessários. Avaliaram-se os estandes finais e as produções de grãos.

Os dados obtidos nos experimentos foram submetidos à análise da variância; as médias dos dados referentes aos fatores qualitativos, comparados pelo teste de Tukey a $5 \%$ de probabilidade, e os dados correspondentes aos fatores quantitativos, submetidos à análise de regressão.

\section{RESULTADOS E DISCUSSÃO}

Houve diferença significativa $(\mathrm{P} \leq 0,01)$ entre as folhas das cultivares avaliadas, em relação à aceitabilidade sensorial (Quadro 1). A aceitação média da cultivar Diacol Calima foi a única distinta significativamente da couve, situando-se, em média, entre os termos hedônicos "gostei ligeiramente" e "indiferente". Para as outras cultivares, a aceitação não foi significativamente diferente da couve, situando-se, em média, entre "gostei moderadamente" e "gostei ligeiramente". A couve foi classificada no termo hedônico "gostei moderadamente" (média de aceitação 6,9), praticamente a mesma da maioria das variedades de feijão testadas. O resultado obtido com 'Diacol Calima' é indicativo de que nem todas as cultivares dessa leguminosa seriam tão bem aceitas como a couve.

Quanto à produção de folhas verdes, não se observaram diferenças significativas $(\mathrm{P}>0,05)$ entre as cultivares de feijão (Quadro 1). $\mathrm{O}$ rendimento variou de $458 \mathrm{~kg} \cdot \mathrm{ha}^{-1}$ a $695 \mathrm{~kg} \cdot \mathrm{ha}^{-1}$, na 'Ouro' e 'Manteigão Fosco' respectivamente, enquanto a couve produz, normalmente, mais de 60 t.ha ${ }^{-1}$ ao ano 
Quadro 1. Aceitabilidade sensorial de seis cultivares de feijão e da couve e produções médias de folhas verdes das cultivares de feijão, com $33 \%$ de desfolhamento

\begin{tabular}{lcc}
\hline Cultivares/Linhagens & Média de aceitação $^{(1)}$ & Produção de folhas verdes $^{(2)}$ \\
\hline Couve & $6,9 \mathrm{a}$ & $\mathrm{kg}^{-1}$ \\
Pérola & $6,4 \mathrm{ab}$ & 436 \\
Ouro Negro & $6,3 \mathrm{ab}$ & 495 \\
Manteigão Fosco & $6,0 \mathrm{ab}$ & 695 \\
Vi. 13-8-3 & $5,9 \mathrm{ab}$ & 469 \\
Ouro & $5,9 \mathrm{ab}$ & 458 \\
Diacol Calima & $5,6 \mathrm{~b}$ & 566 \\
\hline CV (\%) & 35,2 & 30,6 \\
\hline
\end{tabular}

Médias seguidas da mesma letra não diferem significativamente, pelo teste de Tukey, a 5\%. (1) 9: gostei extremamente; 8 , gostei muito; 7, gostei moderadamente; 6, gostei ligeiramente; 5, indiferente; 4, desgostei ligeiramente; 3, desgostei moderadamente; 2 , desgostei muito; e 1, desgostei extremamente. $\left({ }^{2}\right)$ Sem diferenças significativas pelo teste $\mathrm{F}(\mathrm{P}>0,05)$.

(FILGUEIRA, 1982). Quanto a esse aspecto, não se deve comparar a produção de folhas verdes das duas culturas, porque a coleta de folhas dos feijoeiros foi reduzida (33\%). Para o consumidor, elas constituiriam apenas um suplemento a ser usado quando houvesse escassez de outras verduras ou intenção de variar os ingredientes alimentares. Devese considerar, entretanto, que da leguminosa colhemse também os grãos e, em vista de seu ciclo de vida mais curto, pode-se cultivá-la mais de uma vez por ano.

No primeiro experimento, realizado em Coimbra, houve efeito significativo $(\mathrm{P} \leq 0,01)$ das doses de nitrogênio sobre as variáveis analisadas. Com o incremento da adubação nitrogenada, ocorreu aumento linear dessas variáveis (Figuras 1, 2 e 3). Com a dose de 90 kg.ha-1 obtiveram-se produções médias estimadas de folhas verdes, de grãos secos e de proteína nas folhas, de 1.544, 2.270 e 304 kg.ha-1, da 'Ouro Negro', e 1.158, 2.383 e 232 kg.ha-1, da 'Pérola' respectivamente.

Embora no experimento anterior não tenham ocorrido diferenças significativas entre as cultivares quanto à produção de folhas verdes, de acordo com os dados obtidos no presente experimento, foi possível a diferenciação entre as cultivares. Verificou-se que a produção de folhas verdes, com 33\% de desfolhamento, pode ser de 1,5 t.ha-1; ${ }^{-1}$ esse patamar certamente poderá ser ultrapassado, dependendo da cultivar e da adubação utilizadas. EDJE et al. (1976) constataram melhor recuperação dos feijoeiros aos efeitos do desfolhamento, com elevada adubação nitrogenada.

A cultivar Ouro Negro foi superior à Pérola em dois aspectos: produção de folhas verdes e produção de proteína por unidade de área nas folhas, mas em relação ao rendimento de grãos, praticamente houve igualdade entre as duas cultivares. Caso o objetivo do agricultor seja a colheita de folhas verdes e grãos secos, 'Ouro Negro' é melhor opção em relação à 'Pérola', se não houver objeção à cor negra dos grãos daquela cultivar.

Não houve influência significativa $(\mathrm{P}>0,05)$ das cultivares, dos níveis de $\mathrm{N}$ e de sua interação sobre o estande final, que variou de 205 a 274 mil plantas por hectare, portanto, dentro dos limites recomendados para a cultura do feijão (ARAúJO, 1998).

$\mathrm{Na}$ análise química das folhas de couve e da mistura de folhas de feijão, verificou-se porcentagem duas vezes maior de fibra nestas em relação às da couve (Quadro 2). Isso pode ser explicado pela retirada da nervura central da folha da couve, o que não se fez com as dos folíolos de feijão. Durante a análise sensorial, os provadores ressaltaram a textura fibrosa das folhas de feijão, sendo mais acentuada em algumas cultivares. Aquelas com folhas mais fibrosas também foram julgadas mais amargas; provavelmente, se a nervura central dos folíolos tivesse sido eliminada, teriam sido mais bem aceitas.

Nos testes sensoriais, pôde-se observar maior quantidade de água durante o preparo das amostras de couve, até mesmo quando se utilizou igual volume para refogar as folhas de ambas as espécies, enquanto as folhas de feijão apresentavam-se mais ressecadas. Explica-se esse aspecto pelo alto teor de fibra e menor teor de água nas folhas da leguminosa.

Em relação aos teores de carboidratos, gordura e cinza, não houve grandes diferenças entre as duas espécies. Na couve, o teor de proteína foi maior que no feijão. Deve-se ressaltar que a folha de qualquer 


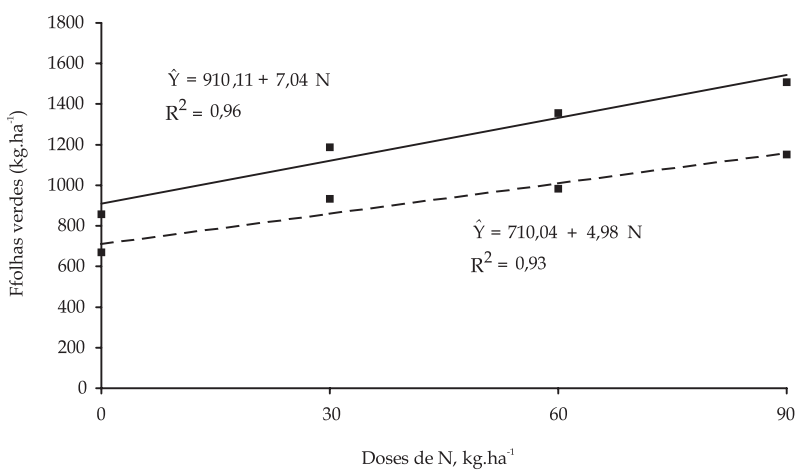

Figura 1. Rendimento de folhas verdes das cultivares Pérola (---) e Ouro Negro (-) de feijoeiro, submetidas a $33 \%$ de desfolhamento, na época da floração, em função de doses de nitrogênio.

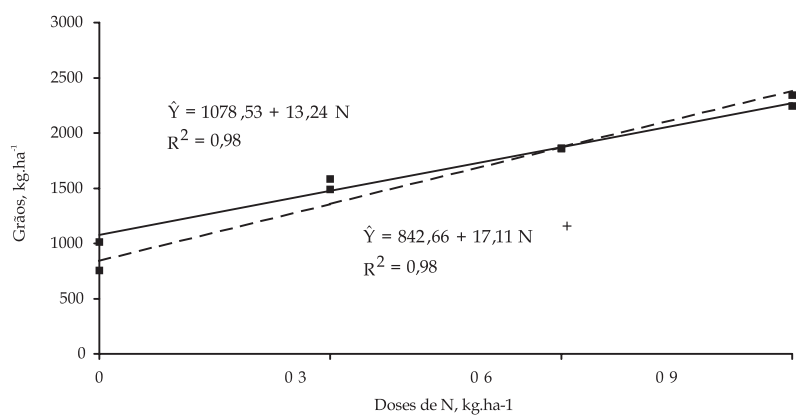

Figura 2. Rendimento de grãos das cultivares Pérola (---) e Ouro Negro (-) de feijoeiro, submetidas a $33 \%$ de desfolhamento, na época da floração, em função de doses de nitrogênio.

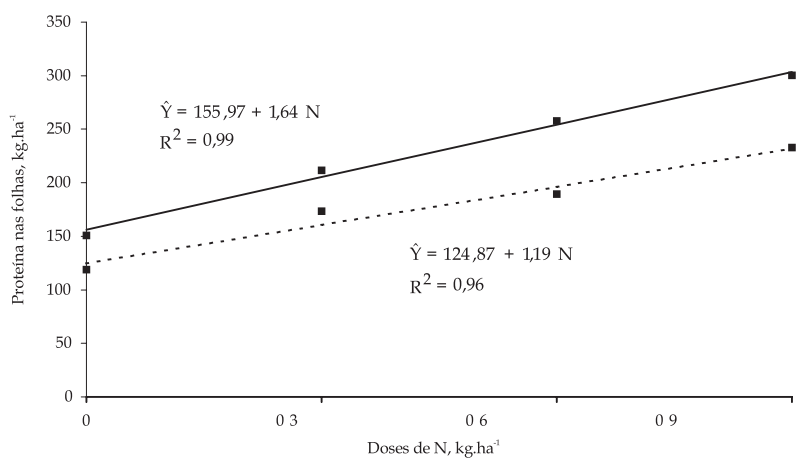

Figura 3. Produção de proteína nas folhas das cultivares Pérola (---) e Ouro Negro (-) de feijoeiro, submetidas a 33\% de desfolhamento, na época da floração, em função de doses de nitrogênio. outra hortaliça é incluída na alimentação humana como complemento de fibras, vitaminas e minerais. Assim, as folhas de feijão não seriam importante fonte protéica, mas, essencialmente, de fibras e minerais.

Quanto ao experimento de níveis e épocas de desfolhamento, houve uma tendência de diminuição gradual nos estandes finais à medida que se aumentava o nível de desfolhamento (Figura 4). Isso demonstra, sobretudo, nos desfolhamentos mais precoces, que a remoção de grande área foliar ocasionou aumento na mortalidade de plantas. Contudo, os estandes finais sempre foram superiores a 250 mil plantas por hectare, população considerada adequada para a cultura do feijão (ARAÚJO, 1998).

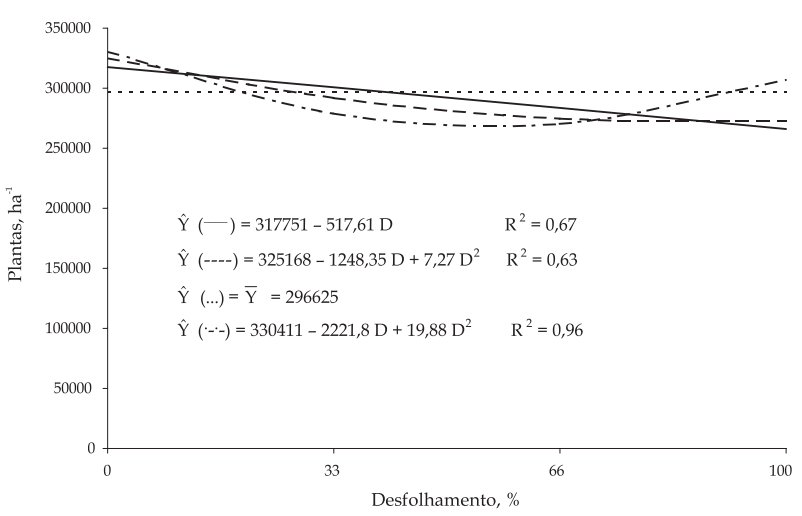

Figura 4. Estande final da cultivar Ouro Negro de feijoeiro, em função de quatro níveis de desfolhamento, realizados aos $25(-), 40(---), 55(\cdots)$ e 70 dias (--) após a emergência.

Os rendimentos foram inferiores a $1.000 \mathrm{~kg} \cdot \mathrm{ha}^{-1}$, apesar da adubação, das capinas, da adequada população de plantas e das irrigações, por causa da elevada incidência de oídio (Erysiphe polygoni), iniciada no período de formação de vagens.

Com $100 \%$ de desfolhamento, obteve-se o tratamento mais prejudicial à produtividade da cultura, em qualquer época de execução (Figura 5). Em todas as épocas, os prejuízos foram crescentes à medida que os níveis de desfolha aumentavam. De modo geral, outros autores obtiveram resultados semelhantes (EDJE et al., 1972; GALVEZ et al., 1977; Chagas et al., 1979; LinK et al., 1980; Mullins et al., 1981; VIEIRA, 1981; BORTOLI et al., 1983; RONZELLI-JÚNIOR et al., 1988; Ablett e SchaAfsma, 1990; Quintela e BARRIGOSSI, 1999).

Ocorreram algumas diferenças entre as épocas de execução da desfolha (Figura 5). Naquelas realizadas aos 25 e 40 dias após a emergência (DAE) houve incremento de produção de grãos, com a desfolha estimada em $30 \%$. Fenômeno semelhante foi 
Quadro 2. Composição química das folhas do feijoeiro e da couve

\begin{tabular}{lcc}
\hline Composição & Couve & Feijão $^{(1)}$ \\
\cline { 2 - 3 } & 8,9 & \\
\cline { 2 - 3 } Água & 28,1 & 4,6 \\
Proteína & 36,2 & 19,3 \\
Carboidratos & 3,3 & 32,2 \\
Gordura & 10,5 & 2,8 \\
Cinza & 13,1 & 11,0 \\
Fibras & & 30,1 \\
\hline
\end{tabular}

(1) Amostra composta de duas cultivares de feijão (Pérola e Ouro Negro).

detectado, também em feijoeiro, por LiNK et al. (1980) em uma cultivar, de quatro testadas, e por QUINTELA e BARRIGOSSI (1999), com a desfolha de $25 \%$ das folhas primárias e com $66 \%$ na fase vegetativa.

Aos 55 DAE, em plena floração das plantas, verificou-se o declínio linear do rendimento do feijão, em virtude do aumento da eliminação da área foliar, mas com $100 \%$ de desfolhamento; essa foi a época menos prejudicial. Outros autores obtiveram resultados diferentes: com o desfolhamento nos estádios de florescimento e formação das vagens ocorrem as maiores reduções na produtividade da cultura (GALvez et al., 1977; MulLins et al., 1981; Bortoli et al., 1983; ABLETT e SchAAFSMA, 1990; Boros e SAWICKI, 1996; QUINTELA e BARRIGOSSI, 1999). Não foi encontrada explicação para essa diferença, possivelmente algum fator não identificado influenciou os resultados, o que constituiria uma exceção e não a regra. Por esse motivo, é mais prudente valer-se das informações dos outros autores quanto à época da desfolha.

Aos 70 DAE, isto é, em pleno período de formação das vagens, o desfolhamento foi realmente prejudicial quando o nível de 33\% foi ultrapassado, concordando com CHAGAs et al. (1979), VIEIRA (1981) e RONZELLI-JúNIOR et al. (1988).

\section{CONCLUSÕES}

1. Em geral, as folhas verdes das cultivares de feijão têm aceitação semelhante às da couve na alimentação humana.

2. Com $33 \%$ de eliminação da área foliar, os feijoeiros podem produzir de 0,4 a 1,5 t.ha-1 de folhas verdes.

3. A composição química das folhas verdes de feijão é semelhante à da couve.

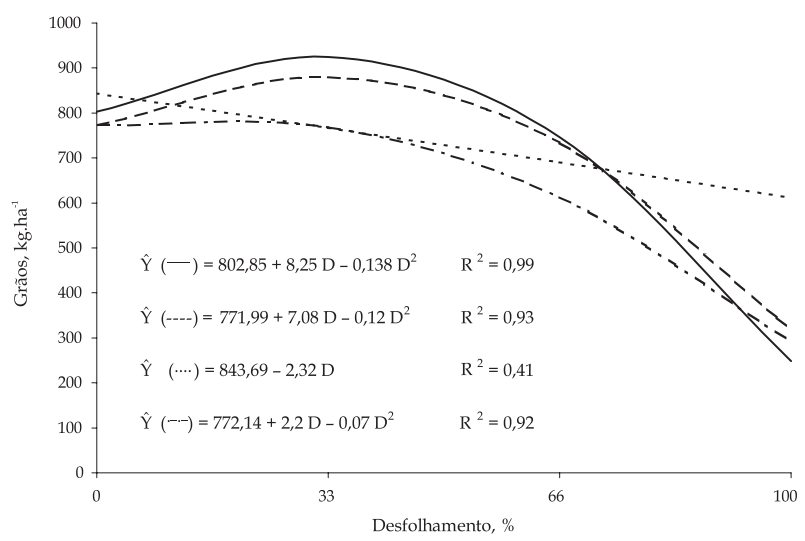

Figura 5. Produção de grãos da cultivar Ouro Negro de feijoeiro, em função de quatro níveis de desfolhamento, realizados aos 25 (-), 40 (---), 55 (...) e 70 dias (.-.-) após a emergência.

4. Quando se pretende maior produção de folhas verdes, proteína (nas folhas) e grãos no feijoeiro, deve-se incrementar a adubação nitrogenada.

5. A época mais adequada para coleta de folhas verdes de feijão é anterior ao florescimento, não devendo ultrapassar o nível de $33 \%$ de desfolhamento.

\section{REFERÊNCIAS BIBLIOGRÁFICAS}

ABLETT, G.R.; SCHAAFSMA, A.W. Effect of defoliation on yield, maturity and seed size of white beans. Annual Report of the Bean Improvement Cooperative, Fort Collins, USA, v.33, p.35-36, 1990.

ARAÚJO, G.A. de A. Preparo do solo e plantio. In: VIEIRA, C.; PAULA-JÚNIOR., T.J.; BORÉM, A. (Eds.). Feijão: aspectos gerais e cultura no Estado de Minas. Viçosa: Editora UFV, 1998. p.99-122.

BOROS, L.; SAWICKI, J. Response of three dry bean genotypes to foliage losses. Annual Report of the Bean Improvement Cooperative, Fort Collins, USA, v.39, p.195-196, 1996.

BORTOLI, S.A.; NAKANO, O.; PERECIN, D. Efeitos de níveis e épocas de desfolhas e dobras artificiais de folíolos sobre a produtividade do feijoeiro (Phaseolus vulgaris L.) em cultura da seca. Anais da Sociedade Entomológica do Brasil, Jaboticabal, v.12, n.1, p.73-83, 1983.

CHAGAS, J.M.; VIEIRA, C.; MAESTRI, M.; CARDOSO, A.A. Resposta de duas variedades de feijão (Phaseolus vulgaris L.) ao desfolhamento artificial. Ciência e Cultura, São Paulo, v.31, n.6, p.683-687, 1979.

COCHRAN, W.G.; COX, G.M. Experimental designs. 2.ed. New York: John Wiley, 1957. 611p. 
EDJE, O.T.; MUGHOGHO, L.K. Photosynthetic efficiency of different zones of the bean plant. Annual Report of the Bean Improvement Cooperative, Lincoln, USA, v.19, p.26-29, 1976.

EDJE, O.T.; MUGHOGHO, L.K.; AYONOADU, U.W.U. Effect of leaf removal on the yield of Phaseolus beans. Malawi Journal of Science, v.l, n.l, p.10-14, 1972.

EDJE, O.T.; MUGHOGHO, L.K.; RAO, Y.P. Effects of defoliation on bean yield. Annual Report of the Bean Improvement Cooperative, Lincoln, USA, v.19, p.29-31, 1976.

FERNÁNDEZ, F.; GEPTS, P.; LOPEZ, G.M.; OSPINA, O.H.F.; HIDALGO, R. Etapas de desarrollo de la planta de fríjol común. Cali: Centro Internacional de Agricultura Tropical, 1982. 26p.

FILGUEIRA, F.A.R. Manual de olericultura: cultura e comercialização de hortaliças. 2.ed. São Paulo: Agronômica Ceres, 1982. 357p.

GALVEZ, G.E.; GALINDO, J.J.; ALVAREZ, G. Defoliación artificial para estimar perdidas por daños foliares en frijol (Phaseolus vulgaris L.). Turrialba, San Jose, v.27, n.2, p.143-146, 1977.

LAMB, E.M.; HARDMAN, L.L.; CLARKE, S.A.; NYABYENDA, P. A survey of bean genotypes grown in Rwanda. Annual Report of the Bean Improvement Cooperative, Geneva, N.Y., v.28, p.17-18, 1985.

LINK, D.; COSTA, E.C.; PANICHI, J.A.V. Efeito do desfolhamento artificial no rendimento de quatro variedades de feijoeiro (Phaseolus vulgaris L.). Revista do Centro de Ciências Rurais, Santa Maria, v.10, n.4, p.329-333, 1980.

MUGHOGHO, L.K.; EDJE, O.T.; AYONOADU, U.W.U. Bean improvement programme in Malawi. Annual Report of the Bean Improvement Cooperative, Lincoln, USA, v.15, p.69-71, 1972.

MULLINS, C.A.; BUHALY, D.L.; KLOSTERMEYER, L.E. Effects of leaf defoliation levels on yield and quality of snap beans. Annual Report of the Bean Improvement Cooperative, Geneva, NY, v.24, p.60, 1981.

QUINTELA, E.D.; BARRIGOSSI, J.A.F. Resposta do feijoeiro a diferentes níveis de desfolha artificial. In: REUNIÃO NACIONAL DE PESQUISA DE FEIJÃO, 6., Salvador, 1999. Resumos Expandidos... Santo Antonio de Goiás: Embrapa Arroz e Feijão, 1999. vol. 1, p.134-137.

RONZELLI-JUNIOR, P.; DAROS, E.; PISSAIA, A.; ZAMBON, J.L.C.; KOEHLER, H.S. Efeitos do desfolhamento sobre os componentes do rendimento e características morfológicas do feijoeiro. I. Cultivar "Carioca". Revista do Setor de Ciências Agrárias, Curitiba, v.10, n.1-2, p.113-118, 1988.

SILVA, D.J. Análise de alimentos (métodos químicos e biológicos). 2.ed. Viçosa: Editora UFV, 1990. 165p.

VIEIRA, C. Effect of artificial defoliation on the yield of two indeterminate bean (Phaseolus vulgaris L.) cultivars. Turrialba, San Jose, v.31, n.4, p.383-385, 1981. 